\title{
К МЕХАНИЗМУ ФОТОИНИЦИИРОВАННОГО ПРЕВРАЩЕНИЯ БЕНЗ(а)ПИРЕНА В ВОДЕ
}

(Представил М. Губергриц)

Известно [ $\left.{ }^{1}\right]$, что фотолиз полициклических ароматических углеводородов (ПАУ) сопровождается генерированием синглетного кислорода $\left({ }^{1} \mathrm{O}_{2}\right)$, который может взаимодействовать с ПАУ и обусловливать их окисление. В частности, этот механизм характерен для фотоокисления (ФО) производных антрацена с электродонорными заместителями в мезо-положении [ $\left.{ }^{2}\right]$. Однако взаимодействием с ${ }^{1} \mathrm{O}_{2}$ и протекающей параллельно димеризацией этих ПАУ трудно полностью описать процесс ФО. Имеются данные [3] об образовании катион-радикалов при фотолизе ПАУ, что в некоторых случаях может существенно влиять на процесс ФО.

Основная задача настоящей работы - на экспериментальном материале оценить роль взаимодействия с синглетным кислородом и образования катион-радикалов при фотоокислении бенз (а)пирена (БП).

\section{Методика и объекты исследования}

Экоперимент проведен в три этапа. Первый из них был посвящен изучению кинетики ФО БП в различных органических растворителях как в присутствии кислорода воздуха, так и при продувке раствора аргоном. Облучение проводили светом с длиной волны 365 нм, выделенным из спектра излучения лампы ДРШ-1000 светофильтром УФС-6 или интерференционным светофильтром. При выборе светофильтра исходили из того, что спектры поглощения растворителя не перекрывают спектров пропускания светофильтра. В качестве растворителей использовались метанол, 96\%-ный этанол, бутанол, октан, бензол, ацетон, хлороформ, четыреххлористый углерод. Все растворители - марки х. ч. и подвергнуты дополнительной очистке.

Второй этап исследования состоял в выявлении роли ${ }^{1} \mathrm{O}_{2}$ при ФО БП. Для этого был осуществлен фотолиз БП в присутствии тушителей ${ }^{1} \mathrm{O}_{2}$ (триэтиламин и азид натрия) и в тяжелой воде. При этом ФО БП проводили полихроматическим светом лампы СВД-120A в омеси этанол-вода (25 об.\% воды) или в этаноле в присутствии кислорода воздуха. С помощью метода фотосенсибилизированного окисления также была предпринята попытка определения константы скорости взаимодействия ${ }^{1} \mathrm{O}_{2}$ с БП. Сенсибилизированное эозином натрия окисление ПАУ проводили в среде бензола при облучении светом с длиной волны 526 нм, выделенным светофильтрами СЗС-22 и ЖС-17 из спектра излучения лампы ДРШ-1000, в присутствии кислорода воздуха. Әозин был нанесен на силикагель с размерами гранул 40/100 $\mu$ (25 мг эозина на 1 г силикагеля). При этом на 50 мл облучаемого раствора брали 0,5 г покрытого эозином силикагеля. 
В третьем цикле экспериментов нзучали ФО ПАУ и бензола в воде при облучении светом (313 нм, 254 нм для бензола и 365 нм для БП), выделенным интерференционным светофильтром из спектра излучения лампы ДКсШ-1000. Концентрация ПАУ не превышала предела их растворимости в воде [4]. За кинетикой убыли ПАУ во всех случаях следили методом прямого спектрофотометрирования на приборе «Specord UV VIS» (до 40\% конверсии вещества). Интенсивность облучения измеряли с помощью ферриоксалатного актинометра. В случае ФО ПАУ в воде поглощение облучаемого раствора определяли прямым измерением. Температура облучаемых растворов составляла $20^{\circ} \mathrm{C}$, и раствор перемешивался магнитной мешалкой. Концентрацию БП в воде определяли измерением флуоресценции октанового раствора при 403 нм и $77 \mathrm{~K}$ на спектрометре «ДФС-12». В качөстве внутреннего стандарта использовали 1,12-бензперилен.

В эксперименте использовали следующие реактивы: нафталин (очищен сублимацией), фенантрен («Союзхимреактив»), антрацен (очищен зонной плавкой), 7,12-диметилбенз (а) антрацен (ДМБА) («Fluka AG»), БП («Fluka AG»), дибенз (a,h)пирен (ДБП) (фирмы «Koch-Light»), эозин натрия («Apolda»), триэтиламин (дважды перегнан), пирен («Союзхимреактив»).

\section{Результаты и обсуждение}

Қинетика ФО БП в органических растворителях при его концентрации от $5 \cdot 10^{-5} M$ и выше описывается уравнением нулевого порядка. Установлено, что квантовый выход (Ф) ФО БП в различных растворителях линейно зависит от его начальной концентрации (рис. 1). Это говорит о вклฺаде темневых реакций в процесс ФО. Интересно отметить, что при использовании в качестве сольвентов четыреххлористого углерода и хлороформа Ф ФО - на несколько порядков выше, чем при использовании других сольвентов. Из данных по ФО БП в различных сольвентах следует, что $\Phi$ его окисления не коррелируется с временем жизни ${ }^{1} \mathrm{O}_{2}$ в примененных растворителях. На незначитель-

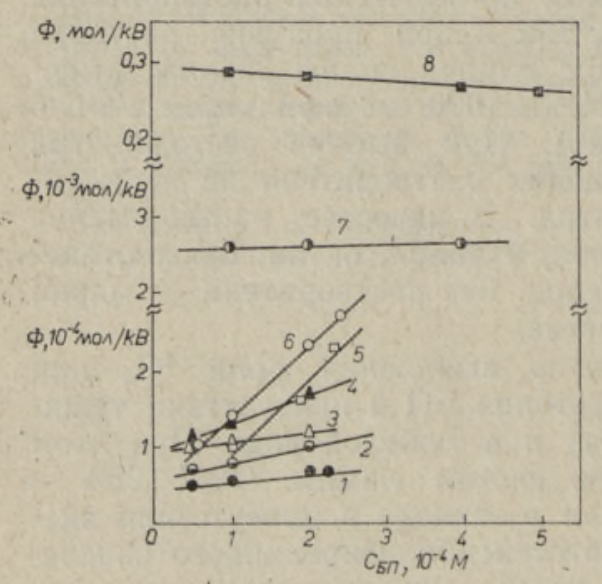

Рис. 1. Квантовые выходы фотоокнсления БП в зависимости от начальной концентрации его в бензоле (1); этаноле (2); $н$-бутаноле (3); ацетоне (4); октане (5); метаноле (6); хлороформе (7) и четыреххлористом углероде (8). Облучали светом с длиной волны 365 нм и в присутствии $\mathrm{O}_{2}$ воздуха.

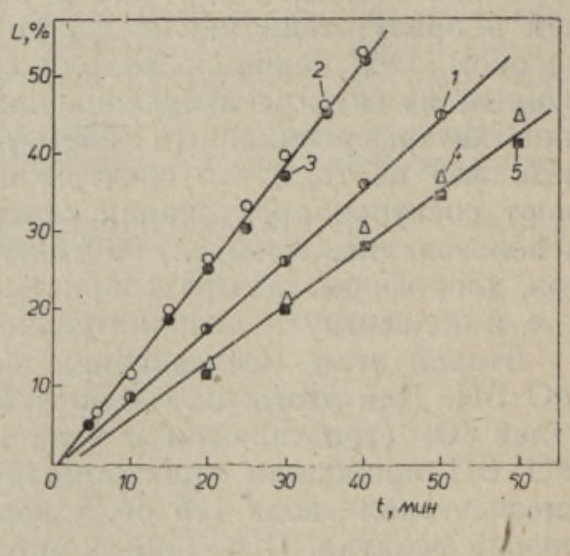

Рис. 2. Кинетика фотоинициированного светом лампы СВД-120 окисления БП при концентрации $4 \mu M$ в присутствин $\mathrm{O}_{2}$ воздуха в этаноле (1); смеси 75 об.\% этанола и 25 об. \% $\mathrm{H}_{2} \mathrm{O}$ (2); смеси 75 об.\% этанола и 25 об. \% $\mathrm{D}_{2} \mathrm{O}$ (3); смеси 75 об. $\%$ этанола, 25 об. $\% \mathrm{H}_{2} \mathrm{O}$ и $0,4 \quad M M$ азида натрия (4) и в этаноле с $0,4 м M$ триэтиламина (5). 
ную роль ${ }^{1} \mathrm{O}_{2}$ при фотолизе БП указывает и то, что скорость его окисления остается постоянной при замене воды на $\mathrm{D}_{2} \mathrm{O}$ в сольвенте этанол-вода (рис. 2), хотя время жизни ${ }^{1} \mathrm{O}_{2}$ в $\mathrm{D}_{2} \mathrm{O}$ в 10 раз болыше, чем в $\mathrm{H}_{2} \mathrm{O}$ [5].

То, что ФО БП ингибируется азидом натрия и триэтиламином (рис. 2), не может служить доводом в пользу доминирующего значения ${ }^{1} \mathrm{O}_{2}$ при ФО, т. к. эти вещества способны к тушению флуоресцентных состояний и катион-радикалов ПАУ $\left[{ }^{6,7}\right]$. Для более четкого выявления роли ${ }^{1} \mathrm{O}_{2}$ при ФО необходимо определить константу скорости его взаимодействия с БП. Для этого провели фотосенсибилизированное эозином окисление БП, ДБП и ДМБА (модельное соединение) в растворе бензола. При фотосенсибилизированном окислении вещества $A$ скорость окисления $V_{A}$ будет зависеть от его начальной концентрации $[A]$ согласно формуле $[8]$ :

$$
\frac{1}{V_{A}}=\frac{1}{V_{\mathrm{I}_{2}}}\left(1+\frac{k_{\text {д }}}{k_{\mathrm{p}}} \cdot \frac{1}{[A]}\right),
$$

где $k_{\mathrm{p}}$ - константа скорости реакции ${ }^{1} \mathrm{O}_{2}$ с $A ; k_{\text {д }}-$ константа скорости дезактивации ${ }^{1} \mathrm{O}_{2} ; V^{{ }^{\prime} \mathrm{O}_{2}}-$ скорость образования ${ }^{1} \mathrm{O}_{2}$. Для ДМБА из зависимости обратная скорость окисления - обратная концентрация (рис. 3) определена константа скорости взаимодействия с ${ }^{1} \mathrm{O}_{2}$, которая составила $(0,8 \pm 1,7) \cdot 10^{7} M^{-1} \cdot c^{-1}$ и удовлетворительно совпала с литературными данными [9]. Для БП и ДБП из аналогичных зависимостей получаются завышенные значения констант скоростей, т. к. обратная скорость образования ${ }^{1} \mathrm{O}_{2}$, равная отсекаемому отрезку на оси ординат, для них гораздо больше (рис. 4 и 5), чем для ДМБА, хотя сенсибилизированное окисление проводилось для всех трех соединений в одинаковых условиях. Әто объясняется протеканием конкурирующих процессов переноса возбуждения от триплетно-возбужденного сенсибилизатора к кислороду. А именно ПАУ как восстановитель может окисляться в результате взаимодействия с триплетом сенсибилизатора или супероксид-анион-радикалом кислорода, который образуется в процессе переноса электрона от восстановленной или триплетной формы сенсибилизатора на кислород $\left[{ }^{10}\right]$. Для оценки реакционной способности БП и ДБП с ${ }^{1} \mathrm{O}_{2}$ можно взять обратную скорость образования ${ }^{1} \mathrm{O}_{2}$, равную определенной в эксперименте по сенсибилизированному

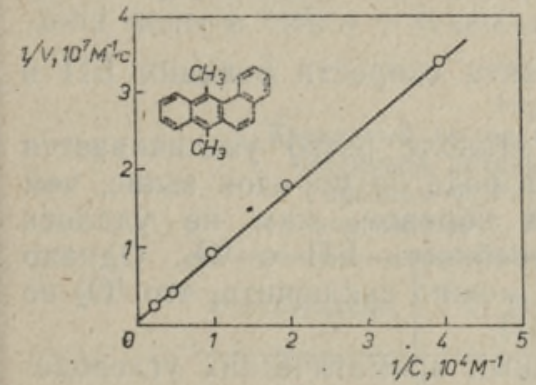

Рис. 3. Зависимость фотосенсибилизированного эозином окисления ДМБА от его начальной концентрацин.

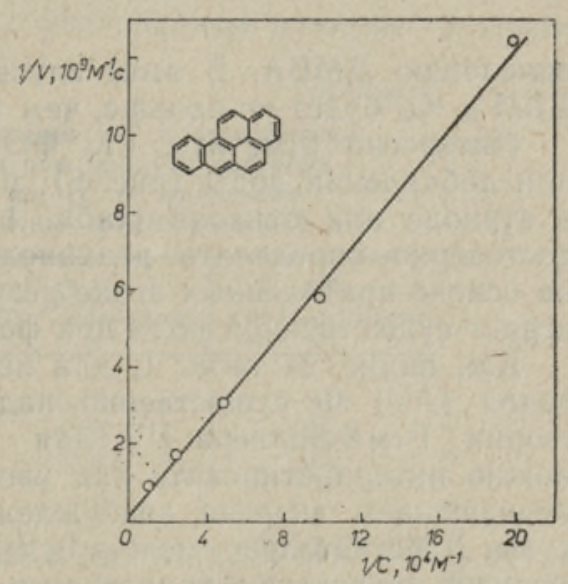

Рис. 4. Зависимость фотосенсибнлизированного эозином окисления БП от его начальной концентрации. 


\begin{tabular}{|c|c|c|c|}
\hline AY & $C, н M$ & $\Phi, м о л / \kappa в а н т ~$ & $-\left(\mathrm{E}_{\mathrm{ox}}-\mathrm{E}_{\mathrm{T}}\right),{ }^{* *}{ }_{\exists} B$ \\
\hline $\begin{array}{l}\text { Бензол } \\
\text { Нафталин } \\
\text { Фенантрен } \\
7,12 \text {-Диметилбенз (а) антрацен } \\
\text { Антрацен } \\
\text { Пирен } \\
\text { Бенз (а)пирен }\end{array}$ & $\begin{array}{l}500 \\
500 \\
500 \\
200 \\
400 \\
500 \\
0,4\end{array}$ & $\begin{array}{l}0,828^{*} \\
0,062^{*} \\
0,058 \\
0,184 \\
3,11 \cdot 10^{-3} \\
1,47 \cdot 10^{-3} \\
2,0 \cdot 10^{-3}\end{array}$ & $\begin{array}{l}1,37 \\
1,10 \\
1,20 \\
0,96 \\
0,76 \\
0,93 \\
0,86\end{array}$ \\
\hline
\end{tabular}

* Қвантовый выход фотоокисления (Ф) для начальной концентрации $(C)$, определенный экстраполяцией из зависимости $\Phi$ от $C$ для более концентрнрованных растворов.

** Потенциалы полуволны одноэлектронного окисления АУ ( $\left.\mathrm{E}_{\mathrm{ox}}\right)$ в ацетонитриле взяты из $\left[{ }^{12}\right]$, а их триплетные энергии $\left(\mathrm{E}_{\tau}\right)$ из $\left[{ }^{13}, 14\right]$.

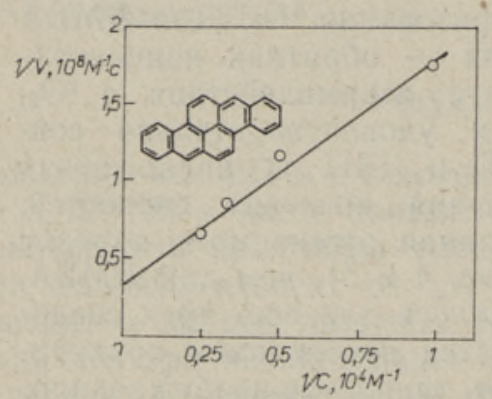

Рис. 5. Зависимость фотосенсибнлизированного эозином окисления ДБП от его начальной концентрации.

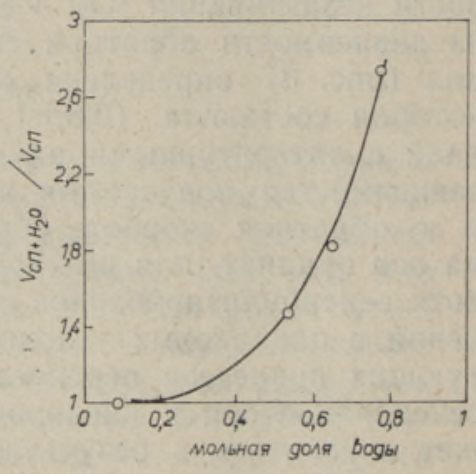

Рис. 6. Изменение относительной скорости фотоокисления БП в смеси этанол-вода от мольной доли воды. Облучали лампой СВД-120, в присутствии $\mathrm{O}_{2}$ воздуха и концентрации БП $4 \mu M$.

окислению ДМБА. В этом случае константа скорости реакции БП и ДБП с ${ }^{1} \mathrm{O}_{2}$ будет не больше, чем $10^{5} M^{-1} \cdot c^{-1}$.

Интересно отметить, что ФО БП в этаноле резко увеличивается при добавлении воды (рис. 6), и Ф ФО в воде на порядок выше, чем в этаноле или бензоле (табл. 1). Таким образом, нам не удалось достоверно определить реакционную способность БП с ${ }^{1} \mathrm{O}_{2}$. Однако на основе приведенных выше результатов можно заключить, что ${ }^{1} \mathrm{O}_{2}$ не нграет существенной роли при фотолизе БП.

Как видно из табл. 1, для незамещенных ароматических углеводородов (АУ) Ф существенно падает от бензола к БП, что согласно теории Рема-Веллера [1'] для внешнесферного переноса электрона можно интерпретировать как увеличение окислительного потенциала с уменышением энергии возбужденного состояния ароматической молекулы. Действительно, между $\lg Ф$ и окислительным потенциалом, уменьшенным на энергию триплетного состояния АУ, наблюдается линейная зависимость (рис. 7):

$$
\lg \Phi=-(7,55 \pm 0,15)-(5,4 \pm 0,8)\left(\mathrm{E}_{\mathrm{ox}}-\mathrm{E}_{\mathrm{T}}\right) .
$$


Рис. 7. Зависимость квантового выхода ФО ароматических углеводородов в воде от потенциала окисления трнплетно-возбужденного состояния.

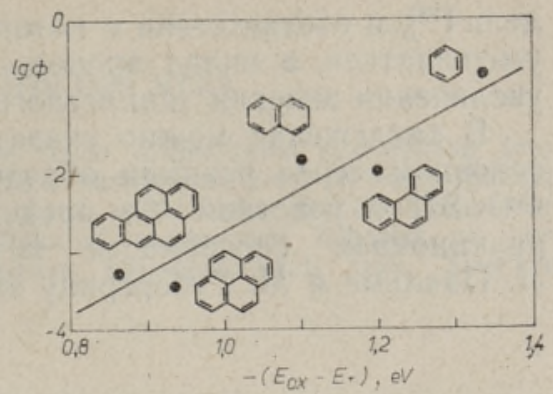

Из этой зависимости выпадают ДМБА и антрацен, окисляющиеся при фотолизе в основном по реакции с ${ }^{1} \mathrm{O}_{2}\left[{ }^{2}\right]$.

Таким образом, можно заключить, что лимитирующей стадией фотолиза соединений, медленно реагирующих с ${ }^{1} \mathrm{O}_{2}$ в воде, является образование катион-радикала АУ в результате переноса электрона от триплетной молекулы на кислород, по упрощенной схеме:

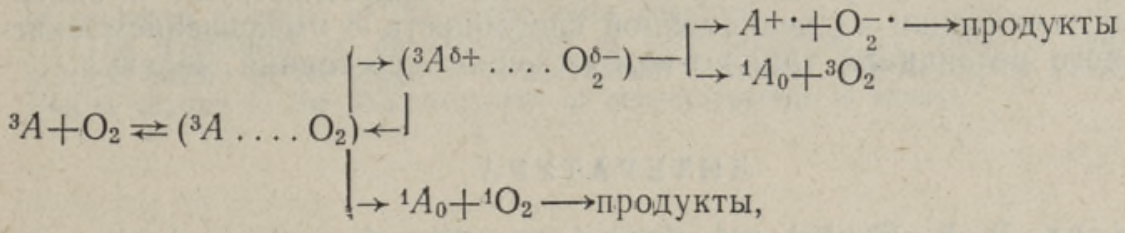

где $\left({ }^{3} A \ldots \mathrm{O}_{2}\right)$ - комплекс столкновения; $\left({ }^{3} A^{\delta+} \ldots . \mathrm{O}_{2}^{\delta-}\right)-$ короткоживущий эксиплекс; $A^{+\cdot}-$ катион-радикал $\mathrm{AУ}^{+} \mathrm{O}_{2}^{-} \cdot-$ анион-радикал кислорода. Из схемы видно, что тушение приплетного состояния АУ кислородом пронсходит, вероятно, по двум конкурирующим механизмам - переноса энергии и переноса электрона, которые, давая различные активные промежуточные продукты, обусловливают окисление АУ. Путь, по которому пойдет окисление АУ, будет зависеть от вклада состояния с переносом заряда в механизм их тушения, а также от реакционной способности АУ с активными частицами $\left({ }^{1} \mathrm{O}_{2}, \mathrm{O}_{2}^{-} \cdot\right)$. Вероятность внешнесферного переноса электрона будет расти как с уменьшением окислительного потенциала триплетно-возбужденного состояния ПАУ, так и с ростом диэлектрической проницаемости растворителя [ ${ }^{11}$ ]. Так, Ф ФО БП (рис. 6) существенно растет с увеличением доли воды в смеси с этанолом, т. е. с увеличением полярности среды.

\section{Таблица 2}

Квантовый выход фотодеградации БП в присутствии кислорода воздуха $\left(\Phi^{\circ}\right)$ и при продуве раствора аргоном (Ф $\left.{ }^{A r}\right) \lambda_{e x}=365 \boldsymbol{\mu}(\boldsymbol{C}-$ начальная концентрация БП в различных растворителях)

\begin{tabular}{|c|c|c|c|}
\hline Растворитель & $C, 10^{-4} M$ & $\begin{array}{l}\Phi^{A r}, \\
10^{-4} \text { Мол/Квант }\end{array}$ & $\frac{\Phi^{O_{2}}}{10^{-4}}$ \\
\hline $\begin{array}{l}\text { Бензол } \\
\text { Октан } \\
\text { Этанол }\end{array}$ & $\begin{array}{l}2,2 \\
2,1 \\
2,2\end{array}$ & $\begin{array}{l}0,484 \\
1,08 \\
0,161\end{array}$ & $\begin{array}{l}0,67 \\
2,28 \\
1,0\end{array}$ \\
\hline
\end{tabular}

Установлено, что существенное влияние на скорость ФО ПАУ оказывает количество растворенного кислорода (табл. 2). А именно, Ф ФО БП значительно падает при продувке системы аргоном.

Полученные в работе результаты подтверждают теоретическую мо- 
дель [ $\left.{ }^{15}\right]$, в соответствии с которой вероятность образования ${ }^{1} \mathrm{O}_{2}$ должна уменышаться, а вклад процесса с переносом заряда должен расти при увеличении энергии триплетного состояния ПАУ.

В заключение можно сказать, что фотолиз БП в воде протекает в основном через реакции образования его катион-радикала. Механизм ФО БП с участием ${ }^{1} \mathrm{O}_{2}$ представляется маловероятным из-за низкой реакционной способности БП. Авторы выражают благодарность Л. Паальме и М. Губергрицу за ценную помощь и советы в работе.

\section{Выводы}

1. Показана незначительная роль синглетного кислорода в фотоокислении БП в водной среде. Наиболее вероятным следует считать механизм фотоинициированното окисления БП, включающий в качестве основной стадию образования его катион-радикала.

2. Результаты определения квантовых выходов фотоокисления БП и ряда ароматических углеводородов в воде свидетельствуют о значительном увеличении их реакционной способности с уменьшением өкислительного потенциала триплет-возбужденного состояния молекул.

\section{Л И Т Е Р А Т У Р А}

1. Kearns, D. R. Physical and chemical properties of singlet molecular oxygen. - Chem. Rev., 1971, v. 71, N 4, p. 395-427.

2. Вембер Т. М., Черка сов А. С. О роли синглетно-возбужденного кислорода в фотоокислении антраценовых соединений. - Теор. и экспер. хим., 1971 , т. 7 , № 3, с. 398.

3. Grellmann, K. H., Watkins, A. R. The photoionisation of perylene in acetonitrile solution. - Chem. Phys. Lett., 1971, v. 9, N 5, p. 439-443.

4. К расноще ков а Р., Губ ерг и ц М. Взаимосвязь реакционной способности и гидрофобности полициклических ароматических углеводородов. - Реакцион. способн. органич. соед., 1976, т. 13, с. 440.

5. Merkel, P. B., Kearns, D. R. Radiationless decay of singlet molecular oxygen in solution. An experimental and theoretical study of electronic-to-vibrational energy transfer. - J. Amer. Chem. Soc., 1972, v. 94, N 21, p. $7244-7253$.

6. Shizuka, H., Nakamura, M., Morita, T. Anion-induced fluorescence quenching of aromatic molecules. - J. Phys. Chem., 1980, v. 84, N 9, p. $989-994$.

7. Reske, L. P., Schmidt, H. Flash photolytic investigations of the electron transfer between aromatic hydrocarbon radicals and tryptophan in micellar solutions. - Photochem. Photobiol., 1979, v. 30, N 6, p. 723-725.

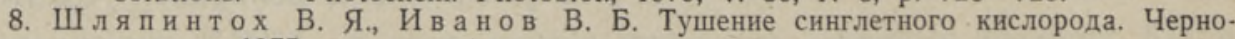
головка, 1975.

9. Stevens, B., Perez Steven, R., Ors, J. A. Photoperoxidation of unsaturated organic molecules. XIV. $\mathrm{O}_{2}{ }^{1} \Delta_{q}$ acceptor properties and reactivity. J. Amer. Chem. Soc., 1974, v. 96, N 22, p. 6846-6850.

10. Свободные радикалы в биологии. М., 1979 , т. 2 , с. 97.

11. Rehm, D., Weller, A. Kinetics of fluorescence quenching by electron and H-atom transfer. - Isr. J. Chem., 1970, v. 8, N 2, p. 259-271.

12. Pysh, E. S., Y ang, N. C. Polarographic oxidation potentials of aromatic compounds. - J. Amer. Chem. Soc., 1963, v. 85, N 14, p. 2124.

13. Нурмухаметов Р. Н. Поглощение и люминесценция ароматических соеди нений. M., 1971 , с. 70.

14. Morgan, D. D., Warshawsky, D., Atkinson, T. The relationship between carcinogenic activities of polycyclic aromatic hydrocarbons and their singlet, triplet and singlet-triplet splitting energies and phosphorescence life times, - Photochem. Photobiol., 1977, v. 25, p. 31-38.

15. Gijzman, O. L. J., $\mathrm{Kaufman}, \mathrm{F}$. Oxygen quenching of aromatic triplet states in solution. Part 2. - J. Chem. Soc. Faraday Trans., 1973, v. 69, N 5, p. $721-726$.

Ннститут химии

Академии наук Эстонской ССР
Поступила в редакцию 19/VI 1981 


\section{BENSO(a)PUREENI FOTOLUUS VEES}

Töös on määratud benso(a)püreeni ja mõnede teiste aromaatsete süsivesinike fotooksüdatsiooni kvantsaagised juhul, kui solvendina kasutatakse vett (benso(a)püreeni puhul ka mōningaid orgaanilisi lahusteid). Ilmneb, et triplettoleku oksüdatsioonipotentsiaali vähenedes reageerimisvõime suureneb. Esitatud mehhanismi kohaselt on benso(a)püreeni fotooksüdatsiooni limiteeriv staadium katioonradikaali teke. Singletse hapniku osa on väheoluline.

\section{SHEVCHUK, V. TCHEKULAYEV}

\section{ON THE BENZO(a)PYRENE PHOTOOXIDATION MECHANISM IN WATER}

The photooxidative quantum yield of benzo(a)pyrene in water and in some organic solvents is reported. The photooxidative quantum yield of several aromatic hydrocarbons in water was determined, and the increase of their reactivity with the decreaseof oxidation potential of the triplet state described.

The mechanism of photooxidation of benzo(a)pyrene in water is suggested to proceed mainly at the stage of cation-radical formation. The negligible contribution of singlet oxygen to the photooxidation of benzo(a)pyrene is shown. 